\title{
A Line Integral Representation of the Physical Optics Far Field from Plane PEC Scatterers Illuminated by Electric or Magnetic Hertzian Dipoles
}

\author{
Arslanagic, S.; Meincke, Peter; Jørgensen, E.; Breinbjerg, Olav
}

Published in:

Proceedings of International Conference on Mathematical Methods in Electromagnetic Theory

Publication date:

2002

Document Version

Publisher's PDF, also known as Version of record

Link back to DTU Orbit

Citation (APA):

Arslanagic, S., Meincke, P., Jørgensen, E., \& Breinbjerg, O. (2002). A Line Integral Representation of the Physical Optics Far Field from Plane PEC Scatterers Illuminated by Electric or Magnetic Hertzian Dipoles. In Proceedings of International Conference on Mathematical Methods in Electromagnetic Theory (Vol. 1, pp. 257259). IEEE.

\section{General rights}

Copyright and moral rights for the publications made accessible in the public portal are retained by the authors and/or other copyright owners and it is a condition of accessing publications that users recognise and abide by the legal requirements associated with these rights.

- Users may download and print one copy of any publication from the public portal for the purpose of private study or research.

- You may not further distribute the material or use it for any profit-making activity or commercial gain

- You may freely distribute the URL identifying the publication in the public portal 


\title{
A LINE INTEGRAL REPRESENTATION OF THE PHYSICAL OPTICS FAR FIELD FROM PLANE PEC SCATTERERS ILLUMINATED BY ELECTRIC OR MAGNETIC HERTZIAN DIPOLES
}

\author{
Samel Arslanagić, Peter Meincke, Erik Jørgensen, and Olav Breinbjerg \\ Ørsted•DTU, Electromagnetic Systems, Technical University of Denmark, \\ Building 348, Ørsteds Plads, DK-2800 Kgs. Lyngby, Denmark, \\ Tel: +45 4588 1444, Fax: +45 4593 1634, E-mail: ob@oersted.dtu.dk
}

\begin{abstract}
We derive a line integral representation of the physical optics (PO) scattered far field that yields the exact same result as the conventional surface radiation integral. This representation applies to a perfectly electrically conducting plane scatterer illuminated by electric or magnetic Hertzian dipoles.
\end{abstract}

\section{INTRODUCTION}

Various line integral representations of the PO scattered field were reported in the literature (see [1]-[2] and previous works referenced therein). In [1]-[2] a line integral representation of the electric and magnetic PO field for arbitrary observation points scattered from a perfectly electrically conducting (PEC) planar plate illuminated by an electric as well as a magnetic Hertzian dipole (HD) was reported. In many applications it is sufficient to know the PO scattered far field. The expressions in [1]-[2] hold also for the case of a far-field observation point but are numerically inconvenient in this case, since they contain terms which do not contribute to the far field, and since they are subject to inaccuracies resulting from the use of a large but finite observation distance. In this paper we derive a line integral representation of the PO scattered far field that, in contrast to the general expressions, includes the distance-dependent part of the far field as an explicit factor. Throughout the paper the time factor $\exp (j \omega t)$ is suppressed.

\section{THE LINE INTEGRAL DERIVATION}

Consider the scattering configuration in Fig. 1. It consists of a plane, arbitrarily shaped,

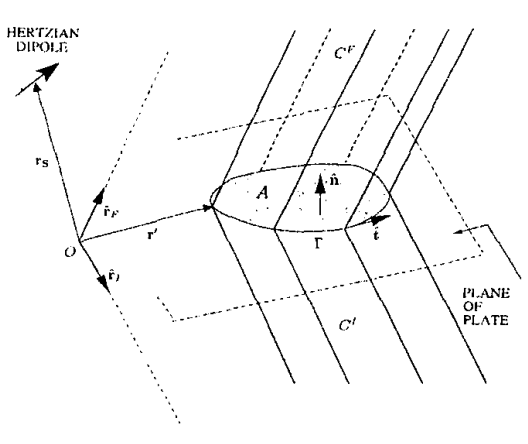

Fig. I Scattering configuration. PEC plate $A$ illuminated by either an electric or a magnetic HD with position vector $\mathbf{r}_{\mathrm{S}}$. The observation point $F$ and the image point $I$, with respect to the plane of the plate, are in the farfield region. Consequently, the truncated cones $V^{O, I}$ from [1],[2] are converted into the cylinders $C^{F, I}$ whose generators extend from the far-field observation and image points, respectively, to the edge $\Gamma$ of the plate. The HD is located in the half space, including the plane of the plate, into which the unit normal vector $\hat{\mathbf{n}}$ of the plate is directed. However, the HD is not to be placed on the plate

itself. In addition, $\hat{\mathbf{n}}$ is related to the edge unit tangent vector $\hat{\mathbf{t}}$ via the right-hand rule. 
The observation point is, without loss of generality, assumed to be located in the same half-space as the HD, i.e., $\hat{\mathbf{r}}_{\mathrm{F}} \cdot \hat{\mathbf{n}} \geq 0$. Finally, it is noted that the HD is not to be located on the surface of the cylinder $C^{F}$.

First, consider the illumination by an electric HD with the electric current density $\mathbf{J}_{\mathrm{e}}=\boldsymbol{\alpha}_{\mathrm{e}} \delta\left(\mathbf{r}-\mathbf{r}_{\mathrm{S}}\right)$ where $\boldsymbol{\alpha}_{\mathrm{e}}[\mathrm{Am}]$ is the electric dipole moment and $\delta$ is the Dirac delta function. By evaluation of the analytical limit of $[2,(11)]$ as the distance $r_{F}$ to the farfield observation point tends to infinity, we find that the magnetic PO scattered far field, $\mathbf{H}_{\mathrm{e}, \mathrm{f}}^{\mathrm{PO}}\left(\mathbf{r}_{\mathrm{F}}\right)$ (subscripts e and frefer to the electric HD illumination and the far-field observation point, respectively), is

$$
\begin{gathered}
\mathbf{H}_{\mathrm{e}, \mathrm{f}}^{\mathrm{PO}}\left(\mathbf{r}_{\mathrm{F}}\right)=\frac{\mathrm{e}^{-j k_{\mathrm{F}}}}{r_{\mathrm{F}}} \int_{\Gamma}\left[\hat{\mathbf{t}} \cdot\left(\mathrm{e}^{j k \hat{\mathrm{F}}_{\mathrm{F}} \cdot \mathbf{r}^{\prime}} \overline{\mathbf{W}}_{\mathrm{e}, \mathrm{f}}\left(\mathbf{r}_{\mathrm{F}}, \mathbf{r}^{\prime}\right)-\mathrm{e}^{j k \hat{\mathrm{r}}_{\mathrm{I}} \cdot \mathbf{r}^{\prime}} \overline{\mathbf{W}}_{\mathrm{e}, \mathrm{f}}\left(\mathbf{r}_{\mathrm{I}}, \mathbf{r}^{\prime}\right) \cdot(\overline{\mathbf{I}}-2 \hat{\mathbf{n}} \hat{\mathbf{n}})\right)\right. \\
\left.+\frac{1}{2 \pi} \mathrm{e}^{j \hat{\mathrm{r}}_{\mathrm{F}} \cdot \mathbf{r}^{\prime}} \hat{\mathbf{n}} \hat{\mathbf{n}} \cdot\left(\hat{\mathbf{t}} \times \mathbf{H}_{\mathrm{e}}^{\mathrm{i}}\left(\mathbf{r}^{\prime}\right)\right)\right] \mathrm{d} \Gamma^{\prime}-\mathbf{H}_{\mathrm{e}}^{\mathrm{i}}\left(\mathbf{r}_{\mathrm{F}}\right) \chi\left(\mathbf{r}_{\mathrm{F}}\right)
\end{gathered}
$$

where the incident magnetic field $\mathbf{H}_{\mathrm{e}}^{\mathrm{i}}$ is given in [5, (12)], $\mathbf{r}^{\prime}$ is the position vector of the integration point and $k$ is the wave number. $\chi\left(\mathbf{r}_{\mathrm{F}}\right)=1$ if the HD is inside the cylinder $C^{F}$ and zero otherwise. The dyad $\overline{\mathbf{W}}_{\mathrm{e}, \mathrm{f}}$ is the far-field version of $[2,(13)]$ and reads

$$
\begin{aligned}
\overline{\mathbf{W}}_{\mathrm{e}, \mathrm{f}}\left(\mathbf{r}, \mathbf{r}^{\prime}\right)= & \frac{\mathrm{e}^{-j k \rho}}{(4 \pi)^{2}}\left(\mathrm{~K}_{1, \mathrm{f}}\left(\mathbf{A}_{\mathrm{f}} \boldsymbol{\rho} \cdot(\overline{\mathbf{I}}-\hat{\mathbf{r}} \hat{\mathbf{r}}) \times \boldsymbol{\alpha}_{\mathrm{e}}\right)\right. \\
& \left.+\mathrm{K}_{2, \mathrm{f}}\left(-\boldsymbol{\alpha}_{\mathrm{e}} \hat{\mathbf{r}}+\overline{\mathbf{I}} \hat{\mathbf{r}} \cdot \boldsymbol{\alpha}_{\mathrm{e}}+j k \mathbf{A}_{\mathrm{f}} \mathbf{B}_{\mathrm{f}}\right)+\mathrm{K}_{3, \mathrm{f}} \mathbf{A}_{\mathrm{f}} \mathbf{B}_{\mathrm{f}}\right)
\end{aligned}
$$

with $\mathbf{A}_{\mathrm{f}}=\hat{\mathbf{r}} \times \boldsymbol{\rho}, \mathbf{B}_{\mathrm{f}}=\hat{\mathbf{r}} \times \boldsymbol{\alpha}_{\mathrm{e}}, \boldsymbol{\rho}=\rho \hat{\boldsymbol{\rho}}=\mathbf{r}^{\prime}-\mathbf{r}_{\mathrm{S}}$ and $\hat{\mathbf{r}}=r^{-1} \mathbf{r}$. The functions $\mathrm{K}_{\mathrm{l}, \mathrm{f}}-\mathrm{K}_{3, \mathrm{f}}$ are

$$
\begin{gathered}
\mathrm{K}_{1, \mathrm{f}}=\frac{1}{\rho^{2}}\left(\frac{j k}{\rho-\hat{\mathbf{r}} \cdot \boldsymbol{\rho}}+\frac{2-\hat{\mathbf{r}} \cdot \hat{\boldsymbol{\rho}}}{(\rho-\hat{\mathbf{r}} \cdot \boldsymbol{\rho})^{2}}\right)-\mathrm{e}^{j k(\rho-\hat{\mathbf{r}} \cdot \boldsymbol{\rho})} \frac{4}{\left(\rho^{2}-(\hat{\mathbf{r}} \cdot \boldsymbol{\rho})^{2}\right)^{2}} \\
\mathrm{~K}_{2, \mathrm{f}}=\frac{1}{\rho} \frac{1}{\rho-\hat{\mathbf{r}} \cdot \boldsymbol{\rho}}-\mathrm{e}^{j k(\rho-\hat{\mathbf{r}} \cdot \boldsymbol{\rho})} \frac{2}{\rho^{2}-(\hat{\mathbf{r}} \cdot \boldsymbol{\rho})^{2}} \\
\mathrm{~K}_{3, f}=-\frac{1}{\rho^{3}}(1+j k \rho)
\end{gathered}
$$

Now the associated electric PO scattered far field is readily found as

$$
\mathbf{E}_{\mathrm{e}, \mathrm{f}}^{\mathrm{PO}}\left(\mathbf{r}_{\mathrm{F}}\right)=-Z \hat{\mathbf{r}}_{\mathrm{F}} \times \mathbf{H}_{\mathrm{e}, \mathrm{f}}^{\mathrm{PO}}\left(\mathbf{r}_{\mathrm{F}}\right)
$$

with $\mathrm{Z}$ denoting the intrinsic impedance of the ambient medium.

Second, consider the illumination by a magnetic HD with the magnetic current density $\mathbf{J}_{\mathrm{m}}=\boldsymbol{\alpha}_{\mathrm{m}} \delta\left(\mathbf{r}-\mathbf{r}_{\mathrm{s}}\right)$ where $\boldsymbol{\alpha}_{\mathrm{m}}[\mathrm{Vm}]$ is the magnetic dipole moment. By evaluating the analytical limit of the general expressions [1], [2], we find that the electric PO scattered far field, $\mathbf{E}_{\mathrm{m}, \mathrm{f}}^{\mathrm{PO}}\left(\mathbf{r}_{\mathrm{F}}\right)$ (the subscript $\mathrm{m}$ refers to the magnetic HD illumination), is given by (7). In (7) we use (2) to obtain $\overline{\mathbf{W}}_{\mathrm{m}, \mathrm{f}}$ as $\overline{\mathbf{W}}_{\mathrm{m}, \mathrm{f}}=-Z \overline{\mathbf{W}}_{\mathrm{e}, \mathrm{f}}$ with $\boldsymbol{\alpha}_{\mathrm{e}}$ replaced by $Z^{-1} \boldsymbol{\alpha}_{\mathrm{m}}$. The incident magnetic field $\mathbf{H}_{\mathrm{m}}^{\mathrm{i}}$ is given in [5, (21)] while the incident electric field is 
$\mathbf{E}_{\mathrm{m}}^{\mathrm{i}}\left(\mathbf{r}^{\prime}\right)=-G\left(\mathbf{r}^{\prime}, \mathbf{r}_{\mathrm{S}}\right)(j k+1 / \rho) \boldsymbol{\alpha}_{\mathrm{m}} \times \hat{\boldsymbol{\rho}}$ where $G\left(\mathbf{r}^{\prime}, \mathbf{r}_{\mathrm{S}}\right)$ is the scalar Green's function.

$$
\begin{aligned}
\mathbf{E}_{\mathrm{m}, \mathrm{f}}^{\mathrm{PO}}\left(\mathbf{r}_{\mathrm{F}}\right)= & \frac{\mathrm{e}^{-j k_{\mathrm{F}}}}{r_{\mathrm{F}}} \int_{\Gamma}\left[\hat { \mathbf { t } } \cdot \left(\mathrm{e}^{j k \hat{\mathrm{r}}_{\mathrm{F}} \cdot \mathbf{r}^{\prime}} \overline{\mathbf{W}}_{\mathrm{m}, \mathrm{f}}\left(\mathbf{r}_{\mathrm{F}}, \mathbf{r}^{\prime}\right)+\mathrm{e}^{j k \hat{\mathbf{r}}_{\mathrm{i}} \cdot \mathbf{r}^{\prime}} \overline{\mathbf{W}}_{\mathrm{m}, \mathrm{f}}\left(\mathbf{r}_{\mathrm{l}}, \mathbf{r}^{\prime}\right) \cdot(\overline{\mathbf{I}}-2 \hat{\mathbf{n}} \hat{\mathbf{n}})\right.\right. \\
& \left.\left.-\frac{Z}{2 \pi} \mathrm{e}^{j k \hat{\mathrm{r}}_{\mathrm{F}} \cdot \mathrm{r}^{\prime}} \mathbf{H}_{\mathrm{m}}^{\mathrm{i}}\left(\mathbf{r}^{\prime}\right) \hat{\mathbf{r}}_{\mathrm{F}}\right)+\frac{1}{2 \pi} \mathrm{e}^{j k \hat{\mathrm{r}}_{\mathrm{F}} \cdot \mathbf{r}^{\prime}}(\overline{\mathbf{I}}-\hat{\mathbf{n}} \hat{\mathbf{n}}) \cdot\left(\hat{\mathbf{t}} \times \mathbf{E}_{\mathrm{m}}^{\mathrm{i}}\left(\mathbf{r}^{\prime}\right)\right)\right] \mathrm{d} \Gamma^{\prime}-\mathbf{E}_{\mathrm{m}}^{\mathrm{i}}\left(\mathbf{r}_{\mathrm{F}}\right) \chi\left(\mathbf{r}_{\mathrm{F}}\right)
\end{aligned}
$$

\section{NUMERICAL RESULTS}

The exactness of the new results is now illustrated through a comparison of the PO scat-

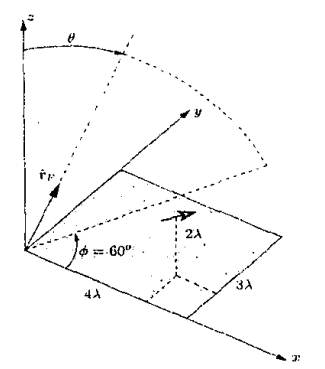

Fig. 2 tered far fields obtained by use of the conventional surface radiation integral and the new line integrals. Scattering by a rectangular plate with the dimensions $4 \lambda$ by $3 \lambda$ ( $\lambda$ being the wavelength) is considered. The plate is located in the $x y$-plane with one of its corners positioned at the origin of the Cartesian $x y z$-coordinate system (see Fig. 2). The HD is placed at $(3 \lambda, 1 \lambda$, $2 \lambda)$ with the dipole moment $\boldsymbol{\alpha}_{e}=(1,1,1)$ Am for the electric HD and $\boldsymbol{\alpha}_{m}=(376,376,376) \mathrm{Vm}$ for the magnetic HD. The observation points are located in the $\varphi=60^{\circ}$ plane with $\theta \in\left[0^{\circ}\right.$, $90^{\circ}$ ]. For this configuration the dipole is inside the cylinder $C^{F}$

for $\theta \in\left[0^{\circ}, 30^{\circ}[\right.$ and outside for $\left.\theta \in] 30^{\circ}, 90^{\circ}\right]$. In Fig. 3 the source is an electric HD and in Fig. 4 the source is a magnetic HD. The figures show the amplitudes of the $\theta$ - and $\varphi$ components of the electric PO scattered far-field pattern. Perfect agreement is found between the two methods of calculation. This was also found for the phase.

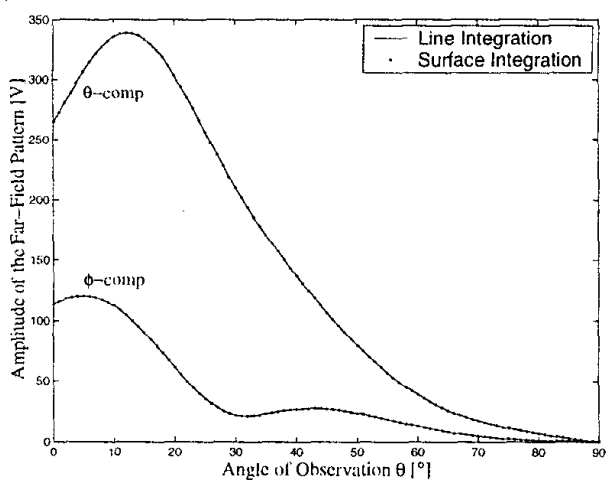

Fig. 3 Electric HD illumination.

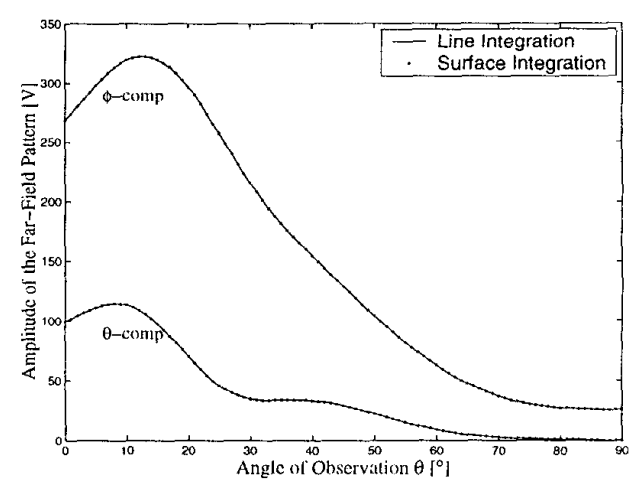

Fig. 4 Magnetic HD illumination.

\section{REFERENCES}

[1] P. Meincke Johansen and O. Breinbjerg, "An Exact Line Integral Representation of the Physical Optics Scattered Field: The Case of a Perfectly Conducting Polyhedral Structure Illuminated by Electric Hertzian Dipoles," IEEE Trans. Antennas Propagat., vol. 43, no. 7, pp. 689-696, July 1995.

[2] P. Meincke, O. Breinbjerg and E. Jørgensen, "An Exact Line Integral Representation of the Magnetic Physical Optics Scattered Field," accepted for publication in IEEE Trans. Antennas Propagat. 